\title{
Qualitative and Phenomenological Research in Mental Health: Mapping as a Proposed Descriptive Method
}

\author{
Bruno Jardini Mäder ${ }^{1}$ (D), Adriano Furtado Holanda ${ }^{1, *}$ (D), \& Ileno Izidio da Costa ${ }^{2}$ (D) \\ ${ }^{1}$ Universidade Federal do Paraná, Curitiba, PR, Brasil \\ ${ }^{2}$ Universidade de Brasilia, Brasília, DF, Brasil
}

\begin{abstract}
The Brazilian Mental Health Care model has been discussed for four decades. In recent years, it has shifted from hospital care to a community Psychosocial Care. Both models coexist, demanding to know how care processes are delivered. This study proposes a qualitative and phenomenological method enough to understand this composition. To this end, we discuss the object of health research, its limits and challenges with the change in population profile and habits, address the concept of Mental Health in its subjective and heuristic sphere - the experience - and its possibility of knowledge through phenomenological research. As a result, we present Network as a communication process experienced by its components. Mapping is proposed as a descriptive method of research and knowledge in Mental Health.
\end{abstract}

KEYWORDS: mapping, phenomenological, mental health, psychosocial care

\section{Pesquisa Qualitativa e Fenomenológica em Saúde Mental: Mapeamento como Proposta de Método Descritivo}

\begin{abstract}
RESUMO - O modelo de Atenção em Saúde Mental vem sendo discutido no Brasil há décadas. Nos últimos anos, passou da atenção hospitalar para Atenção Psicossocial territorializada, modelos que convivem lado a lado, demandando conhecer como se arranjam os processos assistenciais. Este trabalho apresenta o método fenomenológico como potencial para esta compreensão. Discute-se o objeto da pesquisa em Saúde, seus limites e desafios com a mudança no perfil da população e seus hábitos. Aborda o conceito de Saúde Mental em sua esfera subjetiva e heurística - o vivido - e sua possibilidade de conhecimento pela pesquisa fenomenológica. Apresenta-se a Rede como um processo de comunicação vivido pelos seus componentes, e propõe o Mapeamento como método descritivo de pesquisa e conhecimento da Saúde Mental.
\end{abstract}

PALAVRAS-CHAVES: mapeamento, fenomenologia, saúde mental, atenção psicossocial

The Mental Health Care model has been discussed in Brazil for at least four decades. In this process, congresses, experiences, movements, health conferences and publications were held on various topics, among others, the notion of mental disorder, the provision of services and therapies, the care model and the promotion of rights (Amarante, 2007). The main legal framework of this discussion is Law 10.216/2001, which redefined the care model when it replaces hospital care with a territorialized and decentralized one. This replacement, however, was not fully implemented. Today we have the regulation of a Psychosocial Care Network (RAPS) ${ }^{1}$ that coexists with the psychiatric hospital care. Therefore, it is necessary to know this reality, how is organized the Mental Health Care in transition, its difficulties and potentialities.

In this study, we present a qualitative and descriptive research proposal, notably Mapping. For this purpose, it is necessary to reflect on the knowledge practices in Health and their theoretical and ideological background (Almeida

1 In portuguese, Rede de Atenção Psicossocial or Psychosocial Care Network.

\footnotetext{
*E-mail: aholanda@yahoo.com

- Submetido: 08/09/2016; Revisado: 07/03/2018; Aceito: 08/09/2018.
} 
Filho, 2000, Ayres, 2007). Thus, we sought to disentangle health research practices for which the selection of an object is accompanied by a method that already knows it and which is available for its verification (Giorgi, 1985). So, we present the thesis that a research must be conducted primarily by the object to be studied, and not by the method. In other words, the traditional model, with the methodological delimitation in the foreground, masks the results because they are directed to an a priori model, losing important data that appear in the research context.
Therefore, it is imperative to discuss the object of health research and the ways of knowing and approaching it. To this end, we discuss the subject of epidemiology (Public Health axis) and its contemporary challenges with the change in population profile and habits. Then, we approach the concept of Mental Health in its subjective and heuristic sphere - the experience - and its possibility of knowledge through phenomenological research. Finally, we present the Mapping as a form of research and knowledge in Mental Health.

\section{THE OBJECT OF HEALTH RESEARCH}

The premise that health is a right of every citizen and a duty of the state, as stipulated in the Federal Constitution, is the result of an international movement that had great repercussions in Brazil. This movement proposed to go beyond the notion of health as "organ silence", composed of social and psychological determinants, in addition to the physical and biological ones (Scliar, 2007). This proposal implies an extension of biomedical practice to a biopsychosocial practice, embracing citizens in their global and relational needs with a holistic understanding of the subject (Engel, 1977). Thus, Public Health Policies bring together the contemporary challenge of ensuring not only access to qualified health services for the entire population, but also the identification of factors that endanger the health of citizens. In this sense, in the last decades, we have observed efforts for health to be seen as a right and for health professional practices to be displaced from the biomedical model, expanding it. The fundamental orientation is

the new model of care should result in broadening the focus of the current model, thus achieving effective integrality of actions. This expansion is represented by the incorporation of the epidemiological model into the dominant clinical (diseasecentered) model, which requires the establishment of more comprehensive links and processes. (Brasil, 1996)

Epidemiological science, in turn, gathers conditions to identify environmental and social conditions in the healthdisease process,

(...) in human communities, analyzing the distribution and determinants of diseases, health damage and events associated with public health, proposing measures for the prevention, control or eradication of diseases, and building indicators to support planning, administration and evaluation of routine actions, in line with health promotion policies. (Rouquayrol, 2012, p. 345)

This subject is characterized as a fundamental instrument for the organization of Public Health. Historically, especially from the 18th century, epidemiology has emerged as a very effective method of working with the spread of diseases, identifying their cycles and transmission. Diseases such as smallpox, malaria and yellow fever were faced based on epidemiological thinking (Carvalho, 2003). Epidemiological thinking is able to identify social conditions that pose a risk to the health of citizens. In this sense, it has an intersectoral impact, as it indicates important changes beyond the health sector (such as sanitation, housing, social security).

Changes in societal behavior patterns, especially from the second half of the twentieth century, also influence the health needs of the population: a decline in infectious diseases is accompanied by a new look at the morbidity and mortality profile of the population with the growth of diseases with complex multi-causal networks, and determinants such as nutrition, the environment and lifestyles (Carvalho, 2003).

We point to a challenge, if it is not a limit, for epidemiology since they are not just about transmission cycles, but multicausal diseases such as chronic noncommunicable diseases and mental disorders, given their social, personal, subjective and economic determinants.

At this point, we delimit a pertinent question: Epidemiology is fundamental for structuring public policies; after all, with its methods and results, the onset of symptoms is anticipated, promoting prevention. It indicates how to modify the environment or living conditions of a given population or territory by reducing the risk of illness or injury. Thus, epidemiology acts directly against diseases, promoting less prone or less risky environments for disease onset. The limit of this argument for health is found to the extent that, to promote health, we refer to the disease we seek to control. The notion of risk (or the absence of risks) takes centrality, and thus promoting health is equivalent to extinguishing risks to the population (Almeida Filho, 2000).

According to Carvalho (2003), epidemiology is commonly defined as the "study of the determinants of the health-disease process in population groups". The discussion of its object is limited to the understanding of what is disease and its manifestation in the individual and in the populations. It considers the pathophysiological manifestations (signs and symptoms), within reasonably stable patterns, essential for the identification of diseases and that the social and economic aspects are accessory. For Almeida Filho (2000) 
it indicates a crisis in its object, once epidemiology has lost the "safety of disease and causality safety, biostatistics and risk concept, early therapy and prophylaxis" (p. 5).

It is worth to revisit the concept of health and ask ourselves if, for epidemiology intervention object, the following analogy could be made: if for the individual, health would be the silence of the organs, for the population, health would be the silence of the risks. Now, how can we include the psychological, social, and cultural dimensions in the formulation of health policies? Moreover, how to accept the historical transience of these concepts?

Almeida Filho (2000) builds a critique demonstrating that the "epidemiological object has been built according to a monotonous, pseudo-probabilistic, conjunction logic that does not do justice to the richness and complexity of health phenomena" (p. 7). It also points out that the modelobject of epidemiology is a generalist that, by addressing a population, homogenizes and universalizes its object, ideologizing it, highlighting a methodological difficulty for Epidemiology, by questioning whether the role of knowing the heterogeneity of a population is performed by the Clinic or the Social Sciences.

Thus, it is pointed out the need to build another model-object to achieve this end. "The possible object of health-disease-care is one of these complex, plural and context-sensitive heuristic objects, which is only defined in its total configuration, since the apprehension of each of its elements and dimensions does not give us access to integrality of this object"(Almeida Filho, 2000, p. 17).
The polarization in Health-Disease as different things (Health is not disease versus disease is not health, Health promotion versus disease prevention) obscures the positive dimension of Health (Ayres, 2007). If we can understand the manifestation of diseases in individuals with some regularity and normativity, we do not find the same possibility in the positive dimension of health. This is related to the dynamism of life and each one's own search for their health. That said, the health issue is not just about choosing a model, focused on disease or health promotion, as they are not on different levels. "This is not about constructing objects/objectivity, but about configuring subjects/intersubjectivities" (Ayres, 2007, p. 50).

Thus, Health is something that people rediscover every moment tensioning the life and the new, leading the person to the necessity of rearrange. "It is to this process that the relatively large openness of the meaning of health is related, which we find collectively, at different times and social groups, and between different individuals at a given time and place" (Ayres 2007, p. 50). Nothing unheard of so far, since we find much of this discussion in Social Anthropology authors (such as Benedict, Gilberto Velho or Becker, among others) or even from Canguilhem (Faria $\&$ Holanda, 2017). Circumscribing the object of health is a methodological challenge for epidemiology but also for other disciplines as well as for psychology and public health. On the other hand, due to the heuristic nature of this object, we can find in qualitative research a possibility of approximation to this subjective dimension. Mental Health research indicates the path.

\section{THE OBJECT OF MENTAL HEALTH RESEARCH}

The debate about research has a guaranteed place in Mental Health, since the notion of mental illness and care has been discussed for some decades. The very understanding of disease comes into question. Mental Health Care serves not only those who have a symptomatic condition that meets criteria to identify a mental illness, but all who have some kind of suffering, liable to care characterized by the intersubjective relationship, and that transcends the physical and biological aspects as focus (Costa, 2014).

Epidemiological research in Mental Health faces some challenges and difficulties related to data collection instruments, their validity and reliability. Qualitative instruments, such as clinical interview and participant observation, despite having an adequate approach to the object, are open and rely on the effective influence of the interviewer/observer, being difficult to standardize and measure its validity. More pragmatic, closed instruments with simpler application allow the measurement of operative validity and are closer to typical epidemiological studies, but are based on reference standards, whose definition is arbitrary (Almeida Filho, Santana, \& Mari, 1988; Ayres, 2002, 2007).
The most pragmatic, structured, and easy to apply instruments have evolved significantly in recent decades. They allow the measurement of operative validity and have an approach similar to the one adopted by typical epidemiological studies. However, there is still a need for the dissemination of the instruments' theoretical and practical knowledge. Also, they are based on reference standards, which definition is arbitrary, and the determination of symptoms depends on the subjectivity of the evaluator (Gorenstein \& Wang, 2016).

This view finds support in the proposal by Amarante (2007), in which Mental Health is composed of four dimensions: theoretical-conceptual, socio-cultural, legalpolitical and technical-assistance. In this way, the object of mental health can be approached by the assistance dimension researching interventions and their effects, but these carry within them a theoretical-epistemological dimension that has to be addressed. For Almeida Filho, Coelho and Peres (1999), the concept of mental health comprises an object that implies 
employment, job satisfaction, meaningful daily life, social participation, quality of social networks, equity, in short, quality of life. As much as it decrees the end of utopias and the crisis of values, one cannot escape it: the concept of mental health is linked to an emancipatory agenda of the subject, of an inevitably political nature (p. 123).

Ayres (2007) approaches this conception by relating health practice to happiness projects. Health care should not be based on an instrumental approach to which there is a target-subject, but rather promote the sharing of actions in which the subjects (professionals and users) can be authentic and find convenient solutions to their needs (accomplishment at work and relief from suffering, as an example). Happiness here appears as "an eminently political ideal. From our interactions, we reconstruct all the time, historically and socially, the concrete contents of what we increasingly understand by happiness" (p. 56).

We then assume that, in Mental Health, when we take disease or symptom manifestation as an object, we are proposing to know only part of the field. Moreover, we point out that in choosing an object, we are aligned with a comprehensive ideological structure. The lack of reflection on these questions causes the research to fall into a verification of the object already known. Therefore, we have the challenge of knowing the other dimensions that compose Mental Health, besides technical assistance.

In this article, we do not intend to deny the importance of the epidemiological method for Mental Health, after all, it is effective in many aspects, such as pointing out the incidence and prevalence of mental disorders, drawing attention to vulnerable populations and deepening actions for issues such as suicide and self-harm, which face resistance in health policy. On the other hand, the need and challenge of knowing other dimensions, which are beyond diagnostic symptoms and disorders. Even more, in addition to knowing it, proposing public policies to the population, safely and effectively, under this attitude.

\section{A PHENOMENOLOGICAL AND DESCRIPTIVE CONTRIBUTIONTO HEALTH}

Since we are putting Mental Health as an inexhaustibly political and interactional concept, as "one of these complex, plural and context-sensitive heuristic objects" (Almeida Filho, 2000, p. 17), we emphasize the subjective implication that composes it. Moreover, in both academic research and professional practice, the definition of the research or intervention object reproduces the researcher's attitude towards science and the production of knowledge. It is adopted here that phenomenological research involves "the subject of the researcher, that is, the subject-researcher, not only from the perspective of participation as a meaning interpreter, but as a concrete engagement of the latter in the act of research, which would imply discussing the meaning of the own choice of research object" (Holanda, 2003, p. 175, emphasis added).

That said, the Mental Health researcher, especially the one involved in the subjective aspects of the concept, needs to know the engagement in his/her act so as not to inadvertently and simply reproduce a previously given object. Thus, the identification of our previous knowledge about the research object serves to "put them in parentheses". To use the phenomenological method, we reinforce, with Giorgi (2006), that

(a) The researcher should put in parentheses his/her personal prior knowledge and all of his/her theoretical knowledge, i.e., put aside what is possible, what he/she had read or even reproduced, in order to find the best solution for the analysis. This means being based on direct intuition, so all attention should be paid to the moment the phenomenon shows itself in its experience, and (b) The researcher holds the postulation of the existence and reality of the object or state of relations he/she is analyzing. The researcher uses the object or event that is showing itself, but should not present it as actually existing as it is showing itself. It is to be seen as a phenomenon. (p. 355)

If, on the one hand, we need health research that promotes "essential health care based on practical, scientifically sound and socially acceptable methods and technologies" (Declaração Alma Ata, 1978), on the other, we need to reflect on grounding these actions and their objects so that health is not a thoughtless practice of models. In this sense, a contribution of phenomenological qualitative research is the approximation of the heuristic character to its object and clarification of the concept that guides the actions of the Health sector.

In this research proposal, we established the method to better know the field. After all, as the phenomenological method postulates, it is necessary to go to the field already with a prejudice free look so that we can fix our attention on the things themselves and thus direct our look to the essential. In other words, we try to adapt the method to the object, not the object to the method, thus giving primacy to the object and its context, not a theoretical pre-delimitation over the dynamic aspects of the research. Here we have the main difference against epidemiological investigations in which both the object (disease or risk) and the instruments are defined before going to the field.

Thus, at least one descriptive task is placed. According to Dilthey (1894/2002), for the sciences of the spirit (later known as the human and social sciences) description is the 
privileged way of knowing and differs from the methods used by the sciences of nature in that their points of connection are not given by the interpretation of physical facts. The connection in the sciences of spirit is given from inside, in a heuristic way. Description is the first step towards the comprehensive attitude of an experienced process. Dilthey points to a fundamental characteristic of psychic and subjective processes: the experience.

Therefore, we are listing the experience and the processes lived as potent objects to embrace the concept of health without necessarily having to appeal to disease to promote health. So, from there, we think and elaborate health actions and policies. This concept is pivotal to the work of research on subjective aspects, as it is the main difference for the processes of knowing physical aspects. The classic definition of "experience" - Erlebnis in the original - indicates "the active living connection within soul life and the historical world" (Dilthey, 1894/2002, p. 128), that is, as the flow of experiences, that connect the subject to his or her history, culture, context, and, therefore, delimit his constitution; or, as Dilthey (1970/2010) states, is what brings meaning, purpose, and value to actions. In the context of the research, the experience includes the "own real, immediate contents of one's consciousness, the perceptive, representative and ideational data, the emotions, feelings, desires, decisions, the experiences of ecstasy, the doubts and the impulses" (Holanda, 2003, p. 172). Therefore, it encompasses a whole set of intertwining situations.

To perform the descriptive activity, Dilthey (2002/1894) states that

(...) psychological thinking articulates and distinguishes from the given connection. At the service of this descriptive activity are the logical operations of comparing, distinguishing, appreciating degrees, separating and uniting, abstracting, joining parts together, deriving uniform relations from isolated cases, analyzing singular processes, the division. (p. 59)

Unlike traditional epidemiology, we assume the dimension in which the object of Mental Health is not alienated to its researcher. In phenomenology, we are not looking at an exempt, observable, and quantifiable object, but which, when investigated, reveals the attitude and engagement of the researcher himself (or the professional at the cutting edge of politics).

We can take, for example, suffering, family relationships, support networks, territory. If all of these can be investigated by epidemiology, we can also think of them as a phenomenon of human dialogue that include historical, social, cultural, political, power aspects, in short, all possibility of interaction. Thus, the description of the provision of care involves the processes of suffering and illness, care (treatment, follow-up, counseling, welcoming, etc.) and interpersonal relationships that promote health. Therefore, we treat the composition of the network as an experienced process, capable of description and qualitative analysis (Holanda, 2003).

It is also important to emphasize that the notion of health service that appears in our experience is not limited only by its physical structure and legal designation, but mainly by the relationships and exchanges made by the people who compose them. Thus, we start to understand the network of health services as places of human dialogue and sustained by this dialogue. In this case, the experience of offering mental health care in a system that is in model transition and that two different forms live side by side. In this sense, when we ask professionals, for example, how health actions are performed, they will be presented from "immediate real content, perceptive, representative and ideational data, emotions, feelings and decisions, ecstatic experiences, doubts and impetus, finally all the events that intertwine in a "stream of experiences"' (Holanda, 2003, p 172), which can be described and analyzed phenomenologically.

\section{A CUTOUT ON THE DIMENSION OF CARE NETWORK}

Among the possible dimensions of Mental Health, we propose, in this paper, to think about the forms and processes of care. More specifically, care in health services and the health care network system. A health service, like the health network, has a legal designation with structure, minimum staff, objectives, and responsibilities. The way each service (or each network) structures its care, however, has singularities. The care of a service network will not only be known for its physical structure and legal designation, but mainly for the actions, relationships and exchanges - for the lived processes - that the people who compose it perform. Thus, we come to understand the services as spaces of care and the health network as places of human dialogue and sustained by this dialogue.
Care implies actions in the here and now (exemplified by the bond created in territorial actions of micropolitics such as welcoming and home visits, among others), not restricted to actions of symptom removal, but a being-with who accompanies suffering and its overcoming. (Faria, 2017). In this sense, the interest in knowing care is also a way to evaluate the ability of a policy to develop comprehensive care. A SUS (the Brazilian public funded health system) principle, integrality can be summarized as the ability to articulate actions and services (Brasil, 1990).

This integral care, which cannot be known a priori, will be revealed by the people who is part of this network from their immediate real contents, perceptive, representative and ideational data, emotions, feelings and decisions, ecstatic 
experiences, doubts and impulses, finally all the events that intertwine in a 'stream of experiences' that can be described and analyzed phenomenologically (Holanda, 2003).

As we said above that Mental Health is an emancipatory agenda of the subject, of an inexhaustibly political nature, therefore, it is necessary to think about the social and cultural context that a scientific investigation proposes. In Mental Health, the implementation of the Psychosocial Care Network (RAPS) is carried out at the same time as the psychiatric hospital structure continues, even if without the same proportion of what was previously available. Knowing how maintaining two antagonistic models of care influences care and integrality is a matter for the attentive researcher and the engaged worker.

Since Mental Health is made with people within a territory, in each municipality or locality, the provision and construction of the network and care take place differently in their historical, economic, and social contexts. According to the semantic proposition found in Ballarin et al. (2011), it is necessary to know how caring arrangements are formed, unique in each location, made by the participation of all its actors (managers, workers, family members, and users).

Mental Health Care is formed by legal provision, the implementation of services by managers and the performance of professionals (with their theoretical, technical and personal repertoires). Legislation regulates the provision, management and financing of services. Management is responsible for the execution and administrative structure that supports the services. Professionals operate the communication and interaction between services, attention and care of users. It is in this dialogue performed by professionals among themselves and with users that the clinical activity is located. It is this dialogue, lived and experienced, that can be described to understand and map the structure, arrangements, of the Mental Health Care Network. In other words, it is necessary to overcome the essentially "technical" dimension - professionalizing - in order to reach the relational, "mundane" dimension (in the phenomenological sense of being-in-the-world), from a listening system of identities presented - phenomenally presented - in each particular manifestation of the manifest essence of life: thus one must listen to the position of each element of this chain, including those positions that remain static in their traditional modus operandi. Listening occurs through access to the multiple meanings expressed in each manifestation, beyond the traditional epidemiological generalities, and its operationalization is relatively simple, starting with a change of attitude in the access to the meaning of knowledge in this field, that is, to instead of a previously given knowledge, the look is privileged that retrieves the senses immediately given in each experience.

From the notion of object presented, we intend to move away from the simplistic assessment of checking whether the network (our object) is or is not within the scope of ministerial ordinances, but primarily reveal how it is being created, used, felt and perceived by who composes it.

\section{ON MAPPING}

Mapping, as a form of research, has an important range of forms and objectives for professionals who use it. A first idea that arises is linked to territorial elements: a map is the means by which we can see the world or a representation of it. If we take as an example the physical map of a territory, we can identify the rivers that cross it, the houses that are there, its topography. Interestingly, a different map is necessary for each of these goals, etc. If all the information overlaps on the same map, we will have some difficulty interpreting it.

In addition to terrain representation, mapping is used by various areas of the human and health sciences. Santos and Santos (2013) called mapping a census survey in Candomblé yards in the State of Bahia that served as a basis for analyzing their dynamics. Raymundo, Kuhnen and Soares (2011) called mapping a study that describes behaviors of children at school and identifies behavioral categories. From the perspective of the sociology of knowledge, Pohlmann, Bär and Valarini (2014) sought to map normative and cognitive institutions, identify these rules to interpret and analyze them.

In Health, there is a wide variety of use of mapping: by nurses, to identify and compare the languages used in medical records in order to organize and standardize information (Nonino \& Carvalho, 2008), by epidemiology, to identify diseases in a territory and for data georeferencing (Werneck, 2008) by geographers, to identify health risk areas due to contamination in certain soils (Lourenço \& Landim, 2005) and in occupational health to identify risks and outline strategies to combat morbidity and mortality among workers (Vasconcellos \& Ribeiro, 1997).

Still in Health, we can point the practices in Surveillance, as a way to identify the geographical objects, the flow of actions and personal bonds that, when established, form a territory (Monken \& Barcellos, 2005). Oliveira et al. (2011) mapped the flow of breast cancer patients, hospitalizations and outpatient care. They identified the networks and presented the mapping as a tool with important application in planning and improving the distribution of services.

Participatory mapping emerges as a strategy for planning actions of the Family Health Strategy (FHS). From this method, it is possible to identify the health needs of the population and work the bond and ties with the health team (Pessoa, Rigotto, Carneiro \& Teixeira, 2013). Goldstein, Barcellos, Magalhães, Gracie and Viacava (2013) presented a similar proposal for participatory mapping, combining cartography and social participation. They point out the 
optimization of communication in the team and the relevance of the subjectivities present in the health process.

Mapping is used when one has no notion of the whole and one needs to know the object of study, identify the central aspects for research or intervention in health. These forms of mapping permeate the identification of central points and analysis. Important to note that its use goes beyond simply local description or identification of diseases. It is used to know behaviors, understandings and social relations.
Mapping is seen as "an instrument of analysis, interpretation, communication and scenario building" (Goldstein, Barcellos, Magalhães, Gracie, \& Viacava, 2013, p. 55).

The proposal is, through mapping, to sustain a phenomenological investigation within Mental Health, and to instrumentalize both academic research as well as the workers to know the network where they act, its potentialities and its critical nodes.

\section{MAPPING AS A DESCRIPTIVE METHOD IN MENTAL HEALTH}

Mapping can be done in three stages: (a) project design, (b) data collection, and (c) description, organization, and interpretation.

The elaboration of a project serves to identify the context in which the researcher will perform the study or in which the professional is inserted. It is necessary to characterize the network briefly: whether extensive or small, recent or older, observe the territory that is part of the coast, with vigorous or fragile economic activities, among others. This information is important for a prior understanding of composition. In addition, it may be needed to choose where the information will come from: from documentary records, from professionals, or from service users.

This understanding allows for structuring data collection instruments. So, the semi-structured interview appears as a viable data collection instrument, as it allows the researcher to guide and delimit his/her interest in the phenomenon to be researched. It is through the interview that we can get the description of the phenomenon, because with it we are able to facilitate the manifestation of the experiences lived by the collaborators, as it occurs in the experience of the totality of life. It is like a communication vehicle through which it is possible to express conscious experience, which is understood as "(...) a communicative act of a body situated in a certain environment. The message it expresses brings the peculiarity of a lived world. The interest of our investigations is to capture this message, this experienced world" (Gomes, 1997, p. 321). Still, the interview provides us researchers with subsidies for a better expression of the experience of the collaborators and offers the description of the phenomenon as experienced by them, source of the essences that we intend to understand.

We indicate the possibility of finding other ways to collect data such as experiential strategies (such as focus groups) or projective strategies in which the researcher can have contact with the experiences of the participants of his/ her research. The use of closed scales and questionnaires should be well designed so that the interaction is not lost, after all, that is where the qualitative product is extracted. Thus, they can be a good tool to complement expressive techniques.
As a method of analysis, we propose the phenomenological-empirical methodology of Amedeo Giorgi (Giorgi \& Sousa, 2010). Even being criticized (Feijoo \& Goto, 2016), this method can be chosen for a very simple reason: it is an internationally consolidated model, already sufficiently described in the literature, which dialogues with other methods (Branco, 2016). It is also an extremely practical model to absorb and use, thus facilitating operational training (unlike hermeneutic, heuristic, or more analytical methods, which require more experimentation).

If, on the one hand, for the Mental Health worker, this procedure is hampered by the need for recording and transcription, on the other hand, they may have access to internal documents and medical records for a documentary analysis. For data collection, it is essential to understand how communication between professionals and services happens. We must consider communication as the wire that connects points, forming the network. After all, if services do not communicate, we have no network, but two isolated points. Communication is fundamental for structuring care and for comprehensive care.

The analysis should reach the point where it identifies how, when, and with whom services communicate, how they exchange information, what information is relevant, and where information or communication is lacking. When services do not communicate, it is the system user who suffers the main consequences. Following the flow of communication, the professional can draw a map of network services and evaluates care. This map should be described in text form, but then it can also be made graphically. We consider mapping to be a powerful tool for:

a) Knowing and evaluating the operation of a service or network. Mental health care does not have a linear development. We can think of an example of a subject who responds to the attention of the team and who is well or balanced until, by contingencies that are not under the control of the service, getting worse, getting into a crisis, having their suffering increased. This service would need support from others to support this subject fully. Thus, we can question the effectiveness of a mental health service that has no effective communication with other services. There 
is a close relationship between network communication and integrality;

b) Knowing community resources. Territorialized care requires community insertion. The services can approach the social inclusion of its users with agreements with other institutions or exhibitions of the users' works in other spaces. There is also the possibility of volunteering and agreement with universities for internships and teaching. The quality of the care provided indicates whether the care network has social participation or is comprised only by public services;

c) Identify the actors of the process: At first, it is possible to think about the network through the bias of Health, as a place of treatment. On closer examination, we recall that the place of lunacy may be associated with place of danger or unwanted. Thus, the military police or municipal guard, the Justice System and SINASE (National System of Socio-Educational Assistance) are actors of the process not always considered as such, and there are still other actors that can be identified in a mapping.

d) Identifying network failures for integral care. Network failures are related to their communication mode. The quality of the use of referral and counter-referral, specialist orientation, intersectoral meetings, among other strategies, are indicators of this. Often, the users themselves are responsible for the transit of this information from one service to another;

e) Clarifying what is bureaucratic. There is a legal provision for all services. However, transpose it into assistance is not matched in all respects. The mapping can show how this adaptation is made and identify the local characteristics of the care arrangements; f) It can be done in any service. All services have professionals and users, even those who do not claim to be territorialized, such as ambulatory care. However, the Mental Health user will circulate between the different levels of the system and, therefore, there will always be a need to exchange information.

On the other hand, we find and list below the limitations for mapping:

a) It is a different proposal in a historical field and broadly thought out by another view. Epidemiology findings are responsible for extinguishing diseases such as smallpox and malaria, so it is widely recognized. The use and application of the phenomenological method will not have the same receptivity, as it presents the data differently from what the field is used to. Moreover, understanding is not only intellectual: in describing experiences, we invite the reader (receiver of the message) to show themselves, which can generate resistance;

b) Its application is not fast. Each mapping stage takes preparation and application time. In addition, the data display is not graphical or visual. Thus, its application is more suitable for those seeking a more solid analysis of the service than those who need a change or solution of emergency problems;

c) Tension with managers. When you point out the limits and failures of a service, you can lead to the displeasure of those who are responsible for making the decisions. Thus, mapping needs to be the desired action and supported by all staff and service

\section{FINAL CONSIDERATIONS}

Contemporary forms of life impose a practical limit on the biomedical perspective (and its Health model-object), as they have subjective determinants. While biomedical health research presents important and necessary advances, especially related to technological issues, Health implies a heuristic sphere whose applicability is not direct and requires reflection and positioning. We indicate a limit in the construction of knowledge in Health and a possibility of construction. Further, it is necessary to refine the understanding of Health so that it can be promoted, to present alternatives to the most prevalent model and to overcome referral only by the disease.

We indicate a limit in the construction of knowledge in health and a possibility of construction. It is a possible path knowing health through the experience of those who are part of these services: users and professionals. In this sense, these elements of the equation are understood as actors who directly construct the meaning of what is knowledge in health. The production of knowledge implies the development of qualitative methods that can capture the subjective portion of Health. In this way, it is necessary to recognize that its object is not foreign to the researcher or the Health professional and, thus, can be known by the human sciences and by phenomenological research.

The experience lived by Health actors (managers, users and workers), taken as a research object, investigated in a coherent and rigorous manner, provides critical knowledge and the humanization of Health practices. We do not claim competition between the methods of knowledge, but we highlight the complementarity to understand this multifaceted phenomenon that is Health.

Finally, Mapping as a qualitative and phenomenological perspective emerges as a potential form of research, not as an exhaustive and pragmatic assessment for Health Care, but to know what is done, how it is done and what is understood as necessary in Mental health; beyond, equally, from a purely technical or deterministic, linear or static perspective. To use and improve. 


\section{REFERENCES}

Almeida Filho, N. (2000). O conceito de saúde: ponto-cego da epidemiologia? Revista Brasileira de Epidemiologia, 3(1-3), 4-20.

Almeida Filho, N., Coelho M. T. A., \& Peres M. F. T. (1999). O Conceito de Saúde Mental. Revista USP, 43, 100-125.

Almeida Filho, N., Santana, V. S., Mari, J. J. (1988) Princípios de epidemiología para trabajadores de salud mental. Montevideo, Uruguai: Graphis.

Amarante, P. (2007). Saúde Mental e Atenção Psicossocial. Rio de Janeiro, RJ: Fiocruz.

Ayres, J. R. C M. (2007). Uma concepção hermenêutica de Saúde. PHYSIS: Rev. Saúde Coletiva, 17(1), 43-62.

Ayres, J.R.C.M. (2002). Sobre o Risco: para compreender a epidemiologia. São Paulo: Hucitec.

Ballarin, M. L. G. S, Carvalho, F. B., Ferigato, S. H., Miranda, I. M. S., \& e Magaldi, C. C. (2011). Centro de Atenção Psicossocial: Convergência entre Saúde Mental e Coletiva. Psicologia em Estudo, 16 (4), 603-611.

Branco, P. C. C. (2014). Diálogo entre análise de conteúdo e método fenomenológico empírico: percursos históricos e metodológicos. Revista da Abordagem Gestáltica, 20(2), 189-197.

Carvalho, D. M. (2003) Epidemiologia. História e Fundamentos. In R. A. Medronho (Ed.), Epidemiologia. São Paulo, SP: Atheneu.

Costa, I. I. (2014). Sofrimento humano, crise psíquica e cuidado. Brasília, DF: EDUnB.

Declaração de Alma Ata. (1978). Conferência Internacional sobre cuidados primários de saúde, 6-12 de setembro 1978, AlmaAta, USSR. Recuperado de http://www.saudepublica.web. pt/05-promocaosaude/Dec_Alma-Ata.htm

Dilthey, W. (2002) Psicologia e Compreensão. Ideias para uma psicologia descritiva e analitica. Lisboa, Portugal: Edições 70 (Original publicado em 1894).

Dilthey, W. (2010). A construção do mundo histórico nas ciências humanas. São Paulo: Unesp. (Trabalho original publicado em 1970)

Engel, G. L. (1977). The need for a new medical Model: A challenge for Biomedicine. Science New Series, 196 (4286), 129-136.

Faria, N. J. (2017) Noções de cuidado na atenção básica à saúde e Gestalt-terapia. In N. J. Faria \& A. F. Holanda (Eds.), Saúde Mental, Sofrimento e Cuidado - fenomenologia do adoecer e do cuidar (pp. 15-31). Juruá Editora: Curitiba.

Faria, N.J., \& Holanda, A.F. (2017) (Orgs). Saúde Mental. Sofrimento e Cuidado. Fenomenologia do Cuidar e do Adoecer. Curitiba: Juruá Editora
Feijoo, A. M. L. C., \& Goto, T. A. (2016). É Possível a Fenomenologia de Husserl como Método de Pesquisa em Psicologia?. Psicologia: Teoria e Pesquisa, 32(4), e32421. Epub June 22, 2017.https://dx.doi.org/10.1590/0102.3772e3241

Fleitlich B. W., \& Goodman, R. (2000). Epidemiologia. Revista Brasileira de Psiquiatria, 22(Supl. II), 2-6.

Giorgi, A., \& Sousa, D. (2010). Método Fenomenológico de Investigação em Psicologia. Lisboa: Fim de Século.

Giorgi, A. (2006). Difficulties encountered in the application of the phenomenological method in the social sciences. Análise Psicológica, 3(XXIV), 353-361.

Goldstein, R. A., Barcellos, C., Magalhães, M. A .F. M., Gracie, R., \& Viacava, F. (2013). A experiência de mapeamento participativo para a construção de uma alternativa cartográfica para a ESF. Ciência \& Saúde Coletiva, 18(1), 45-56.

Gomes, W. B. (1997). A entrevista Fenomenológica e o Estudo da Experiência Consciente. Psicologia USO, 8(2), 305-336.

Gorenstein, C., \& Wang, Y. P (2016). Fundamentos de Mensuração em Saúde Mental. C. Gorenstein, Y. P. Wang, \& I. Hungerbühler (Eds.), Instrumentos de avaliação em Saúde Mental [recurso eletrônico]. Porto Alegre: Artmed, E-Pub.

Holanda, A. F. (2003). Fundamentação Fenomenológica da Pesquisa do Vivido. In I. I. Costa, A. F. Holanda, \& M. I. Tafuri (Eds.), Ética, Linguagem e Sofrimento. Brasília, DF: Abrafipp.

Monken, M., \& Barcellos, C. (2005). Vigilância em saúde e território utilizado: possibilidades teóricas metodológicas. Cadernos de Saúde Publica, 21(3), 898-906.

Nonino, F. O. L., \& Carvalho, E. C. (2008). A utilização do mapeamento cruzado na pesquisa enfermagem: uma revisão da literatura. Revista Brasileira de Enfermagem, 61(6), 872-877.

Pessoa, V. M., Rigotto, R. M., Carneiro, F. F., \& Teixeira, A. C. A. (2013). Sentidos e métodos de territorialização na atenção primária à saúde. Ciência \& Saúde Coletiva, 18(8), 2253-2262

Rouquayrol, M. Z. (2012) Contribuição da epidemiologia. G. W. S. Campos (Ed.), Tratado de saúde coletiva ( $2^{\mathrm{a}}$ ed. rev.). São Paulo, SP: Hucitec.

Scliar, M. (2007). História do Conceito de Saúde. PHYSIS: Rev. Saúde Coletiva, 17(1), 29-41.

Vasconcellos, L. C. F., \& Ribeiro, F. S. N. (1997). Investigação epidemiológica e intervenção sanitária em saúde do trabalhador: o planejamento segundo bases operacionais. Cadernos de Saúde Pública, 13(2), 269-275. 